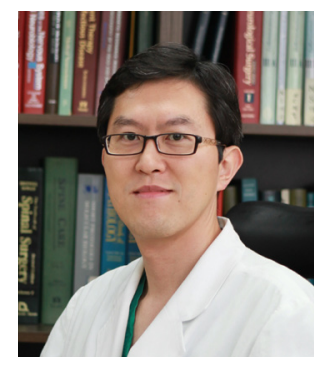

Dong-Hyuk Park

Department of Neurosurgery, College of Medicine, Korea University, Seoul, Korea

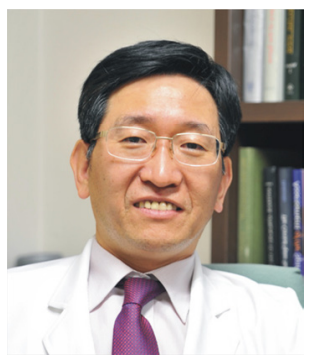

Sang Gu Lee

Department of Neursurgery, Gil Medical Center, Gachon University, Incheon, Korea

\section{We Have a Historical Inaugural Issue of JNIC ahead}

We are very pleased to announce that the official English journal of the Korean Neurointensive Care Society, Journal of Neurointensive Care (JNIC), have launched in October 2018. Since the Korean Neurointensive Care Society was founded as a division of the Korean Neurosurgical Society, we have deeply felt the need for official journals. In the meantime, the former presidents and the executives have been making efforts for the publication of the journal. Finally, in December of 2017, we started to prepare the launching of the English Journal by the resolutions of the executives including the present president, professor Yong Ko. We have repeatedly held meetings with editorial committee members and related persons and finally published an inaugural issue with the dedication of all authors, editors, and reviewers for the first issue.

The JNIC is the official English journal of the Korean Neurointensive Care Society and will be published twice a year. The JNIC publishes important papers covering the whole field of neurosurgical intensive care unit, including studies in neuroscience, neurology, neurocritical care and basic researches. Studies on rare cases and technical notes of special instruments or equipment that might be useful to the field of neurosurgical intensive care are also acceptable. Drawing upon the expertise of an interdisciplinary team of physicians from neurosurgery, neurology, anesthesiology, critical care, and nursing backgrounds, JNIC covers all aspects neurosurgical intensivists need to be aware of in order to provide optimal patient care.

In the future, the editorial committee of JNIC will do its best for the continuous development and become an international journal without being satisfied with the domestic journal. On the basis of JNIC, we will make an effort for the Korean Neurointensive Care Society to become a member of the Korean Medical Association. To do this, We would like to ask all members of Korean Neurosurgical Society and readers to be enthusiastic supporters and contributors to the JNIC.

Lastly, we would like to express special appreciation to professor Yong Ko, the present president of the Korean Neurointensive Care Society, professor Jun Seok W. Hur, an editorial staff, and the other editorial committee members for the publication of this journal.

Dong-Hyuk Park, M.D., Ph.D., Sang Gu Lee, M.D., Ph.D.

Editors-in-chief 